\title{
MOVIMENTOS “ESPONTÂNEOS”: a resistência dos trabalhadores migrantes nos canaviais
}

\author{
Marilda Aparecida Menezes* \\ Maciel Cover**
}

\begin{abstract}
Neste artigo, analisaremos algumas formas de resistência de trabalhadores migrantes de áreas rurais da região Nordeste que labutam na colheita da cana-de-açúcar nas usinas sucroalcooleiras do Estado de São Paulo. Privilegiamos a análise de alguns movimentos "espontâneos" protagonizados pelos cortadores de cana-de-açúcar nomeados como "paradeiros" ou "greves", os quais ocorreram no período de 2007 a 2012. Nossa proposta é compreender esses movimentos, como se inicia a ação, se existem lideranças, que estratégias são utilizadas para mobilizar os trabalhadores, que outros atores sociais estão envolvidos: sindicatos, procuradores do trabalho e pastoral dos migrantes. O artigo é fundamentado em diários de campo, entrevistas semiestruturadas com trabalhadores e sindicalistas, artigos de jornais e documentação audiovisual. Essas ações de resistência acontecem em um período de transformações das relações de trabalho, marcadas pelo contexto de crescente mecanização do corte de cana e de uma maior fiscalização das condições de trabalho promovidas pelo Ministério do Emprego e Trabalho e pelo Ministério Público do Trabalho.
\end{abstract}

PalAvras-Chave: Trabalhadores migrantes. Resistência pública. Greves. Agronegócio.

\section{INTRODUÇÃO}

A demanda por etanol brasileiro, desde a década de 1990, tem gerado uma expansão considerável da área plantada com cana de açúcar no Estado de São Paulo, que saltou de 2.484.790 hectares em 2000 para 4.986 .634 hectares em 2010 (Baeninger et al., 2013) com diversas consequências no meio ambiente, substituição de áreas de culturas alimentares e aumento da contratação de trabalhadores migrantes. Até o início da década de 1990, os trabalhadores procediam principalmente da região mineira do Vale do Jequitinhonha e da Bahia. A partir de 1990, cresce a contratação de trabalhadores de outros estados da região Nordeste, como Paraíba, Piauí, Pernambuco, Ceará e Maranhão.

A partir da década de 2000, o setor tem se caracterizado por uma intensificação da

\footnotetext{
* Universidade Federal de Campina Grande. Av. Aprigio Veloso, 882. Cep: 58429140. Bodocongo - Campina Grande - Paraíba - Brasil. menezesmarilda@gmail.com

${ }^{* *}$ Universidade Federal do Tocantins. Departamento de Educação do Campo, UFT, Campus de Tocantinópolis.

Av. N. Sra. de Fátima, no 1558, Céu Azul. Cep: 77900.000.

Tocantinópolis - Tocantins - Brasil. macielcover@gmail.com
}

mecanização do corte de cana. Embora esteja ocorrendo uma diminuição da quantidade de trabalhadores nessa atividade, não há uma eliminação total do corte manual, porque a colheita mecânica não acontece de maneira homogênea em todas as usinas e nem na totalidade de cada usina, devido às variações do relevo, ao solo e à qualidade da cana. Os dados do Ministério do Trabalho e Emprego, em julho de 2010, mostram que 163.272 trabalhadores foram contratados nas atividades de cultivo e corte da cana no estado de São Paulo (Baccarin \& Junior 2010). Estima-se que $40 \%$ são migrantes oriundos de outros estados (Unica, 2008).

Embora haja uma disponibilidade de trabalhadores na região nordeste, entendemos que a contratação de trabalhadores migrantes é uma estratégia política de dominação e controle das usinas. O sistema de recrutamento e seleção é realizado por agentes mediadores, chamados turmeiros, chefes de turma ou arregimentadores, que são responsáveis por selecionar "bons trabalhadores", ou seja, aqueles que tenham boa produtividade, não faltem ao trabalho, sejam obedientes às regras da usina 
e aos chefes. ${ }^{1}$ Os trabalhadores são homens e jovens, a maioria está na faixa etária de 18 a 30 anos (Silva, 2006; Cover, 2011) e foram socializados no trabalho agrícola, pois seu corpo está disciplinado para o trabalho pesado do corte de cana. Vários estudos (Alves, 2007; Novaes e Alves, 2007; Silva, 2006; Scopinho, 2000) revelam o aumento da exploração e a degradação das condições de trabalho. As médias de produtividade têm aumentado: na década de 1980, as usinas exigiam que o trabalhador cortasse, em média, cinco a oito toneladas de cana, por dia; em 1990, essa média sobe para oito a nove toneladas por dia; em 2000, ela passou para 10 toneladas por dia e para doze a quinze toneladas por dia (Silva, 2006). Além da intensidade do trabalho, que ocasiona um desgaste prematuro, doenças e até casos de morte, ${ }^{2}$ as formas de controle sobre os trabalhadores estão presentes em seus espaços de moradia, como é o caso dos alojamentos (Menezes, 2002; Cover, 2011).

Nossa proposta, neste artigo, é compreender algumas formas de resistência que emergem entre os trabalhadores migrantes face às relações de dominação nas usinas de cana de açúcar do Estado de São Paulo. Analisaremos as ações públicas e coletivas, como as greves em usinas do Estado de São Paulo, ${ }^{3}$ que são • ações iniciadas de forma autônoma e "espontâస్ nea”, ou seja, na sua preparação e emergência não têm a condução do sindicato ou de outros สี่ movimentos sociais, embora, no decorrer da mobilização, outros atores possam entrar no cenário, como lideranças sindicais, Ministério do Trabalho e Procuradoria do Trabalho. Ten\& taremos problematizar alguns pontos da emer\& gência e desenvolvimento dessas greves, como กิ

$\therefore{ }^{1}$ Para um detalhamento maior dessa questão ver Menezes, s. Silva e Cover (2012)

${ }^{2}$ Os trabalhos de Silva, Nunes e Costa (2013) e de Silva, Bueno e Melo (2014) e de Alves (2006) apresentam um ¥ panorama da situação de degradação física de trabalhadores em canaviais, decorrente das condições de trabalho e "paradeiros", conforme analisou Silva (2011). se inicia a ação, se existem lideranças, que estratégias são utilizadas para mobilizar os trabalhadores e que atores sociais estão envolvidos: sindicatos, procuradores do trabalho e agentes da Pastoral dos Migrantes.

Tivemos a oportunidade de acompanhar o caso da greve na Usina Vista Alegre em Itapetininga (SP) em setembro no ano de 2011. Os trabalhadores, que eram da região de São José de Piranhas, Estado da Paraíba, e do município do Barro, Estado do Ceará, realizaram uma paralisação de duas semanas, exigindo pagamento justo e melhores condições de moradia. O artigo tomará o caso dessa greve como objeto de análise. Utilizaremos como fontes de pesquisa os diários de campo, entrevistas semiestruturadas com trabalhadores e sindicalistas, artigos de jornais e documentação audiovisual. Os relatos, colhidos em entrevistas gravadas em áudio e em vídeos, mostram as péssimas condições de alojamento e o descumprimento do preço da cana cortada. Estruturamos nossa argumentação em três partes. Na primeira parte - "Formas públicas de resistência: os canavieiros também fazem greve" -, faremos uma breve análise das formas de resistência a partir das noções de discurso oculto e público do cientista político e antropólogo James Scott (1985), (1990) e das paralisações nas usinas do Estado de São Paulo ocorridas no período de 2008 a 2013. Na segunda parte - "O caso da greve da usina Vista Alegre" -, privilegiamos a análise dessa ação coletiva, para compreender como se inicia a ação, se existem lideranças, que estratégias são utilizadas para mobilizar os trabalhadores, que outros atores sociais estão envolvidos: sindicatos, procuradores do trabalho e Pastoral dos Migrantes. Por fim, esboçaremos algumas considerações sobre a autonomia dos trabalhadores que participam desse movimento "espontâneo" e a relação com o movimento sindical. 


\section{FORMAS PÚBLICAS DE RESISTÊNCIA: os canavieiros também fazem greve}

Para compreender a emergência desses movimentos "espontâneos", estamos nos fundamentando na concepção de "resistência cotidiana” proposta por James Scott (1985, 1990, $2002)^{4}$ e os conceitos de discurso oculto e discurso público.

O discurso oculto é caracterizado por ações individuais de resistência, dissimuladas, fragmentadas ou invisíveis. Nos termos de Scott (1990, p. 4), são ações que acontecem fora do palco (offstage), "para além da observação direta de detentores do poder". Exemplos dessa prática são: rumores, fofocas, folclore, piadas, músicas, rituais, códigos e eufemismos (Scott, 1990, p. 19).

Discurso público são ações de resistência pública, dirigidas àqueles que estão em posições de dominação:

Eu usei o termo "discurso público" como um caminho abreviado para descrever as interações abertas entre subordinados e aqueles que os dominaram [...]. Público aqui se refere à ação que é abertamente dirigida à outra parte nas relações de poder e discurso é usado quase em seu sentido jurídico (processo verbal) de um registro completo do que foi dito. Este registro completo, entretanto, pode também incluir atos não verbais, tais como gestos e expressões. (Scott, 1990, p. 2)

A análise de algumas formas cotidianas de resistência foi objeto de pesquisa em alguns de nossos trabalhos (Menezes, 2002; Cover, 2011) e em Silva (2011). Analisamos expressões do discurso oculto tais como ocultação de serviço mal feito, absenteísmo, códigos secretos de comunicação entre os trabalhadores, confrontos pessoais entre trabalhador e os chefes imediatos. Também observamos algumas formas invisíveis de resistência às regras nos alojamentos, como assistir TV em horários não permitidos.

Além dessas práticas de resistência, há

${ }^{4}$ As ideias de James Scott foram objeto de duas resenhas bibliográficas: a de Menezes (2002) e a de Monsma (2000). também formas públicas de reivindicação das demandas, como paralisações, greves, passeatas, protestos. Tal é o caso dos "paradeiros", nomeação dada às revoltas "espontâneas” de trabalhadores migrantes, originários de regiões rurais do semiárido nordestino, que trabalham no corte de cana-de-açúcar no litoral do Estado de Alagoas (Silva, 2011). ${ }^{5}$

Sobre as greves "espontâneas", tentamos buscar informações em outras fontes, como o site da Federação dos Empregados Rurais do Estado de São Paulo (FERAESP), a Pastoral dos Migrantes e alguns sindicatos da região canavieira, mas não havia registro dessa forma de mobilização dos trabalhadores. Realizamos um levantamento a partir de notícias de veículos de imprensa e contabilizamos 14 registros de greves de canavieiros de 2007 a 2013. As fontes das notícias são diversificadas, aparecendo registros de manifestações de cortadores de cana em sítios eletrônicos de jornais de circulação regional (O Estado de São Paulo, Folha de São Paulo, O Diário, TV TEM), entidades sindicais (CTB - Confederação dos Trabalhadores do Brasil) sítios independentes (Blog do Sakamoto, Portal Mídia Independente) e partidos políticos (Portal do PSTU, Portal Vermelho). Contabilizamos 14 greves, indicadas no Quadro 1.

Os motivos das greves podem ser agrupados em três pontos: questões salariais, preço da cana e condições de alojamento. Há casos em que os trabalhadores conseguem seus pleitos, mas, em outros, não obtêm sucesso. Todavia isso não significa que a greve, como forma de resistência, venha a ser descartada pelos trabalhadores, pois esse tipo de paralisação ocorre com regularidade.

O reconhecido jornalista Leonardo Sakamoto veiculou uma notícia a respeito das características dessas greves, ao relatar os acontecimentos de 2008 no estado de São Paulo:

"Foi quase uma Guariba". A frase é do sindicalista Zaqueu Ribeiro de Aguiar, da Federação dos Empre-

${ }^{5}$ Para um detalhamento sobre os paradeiros de Alagoas, ver a tese de doutorado de Paulo Cândido da Silva (2011). 
Quadro 1 - Relação de mobilizações de trabalhadores nos canaviais no período de 2007 a 2013, noticiados pela imprensa

\begin{tabular}{|c|c|c|c|c|c|c|}
\hline Período & Região & Usina & Trabalhadores & Motivo & Desfecho & Fonte \\
\hline Junho 2007 & Araraquara, SP & Diversas & 5000 & Reajuste salarial & Sem informação & Portal do PSTU \\
\hline Junho 2008 & $\begin{array}{l}\text { Paraguaçu } \\
\text { Paulista, SP }\end{array}$ & Cocal & 300 & $\begin{array}{l}\text { Aumento salarial e melhores } \\
\text { condições nos alojamentos }\end{array}$ & $\begin{array}{l}\text { Demissão dos } \\
\text { trabalhadores }\end{array}$ & $\begin{array}{l}\text { Jornal O Diário de } \\
\text { Ribeirão Preto }\end{array}$ \\
\hline Agosto 2008 & Ribeirão Preto, SP & Bela Vista & Sem informação & Reajuste no preço da cana & $\begin{array}{l}\text { Aumento em } 10 \% \text { no } \\
\text { preço da cana cortada }\end{array}$ & Folha de São Paulo \\
\hline Agosto 2008 & Pontal, SP & Bela Vista & 150 & $\begin{array}{l}\text { Reajuste de } 10 \% \text { no preço } \\
\text { da cana }\end{array}$ & $\begin{array}{l}3 \text { lideres presos e } 6 \\
\text { feridos pela polícia }\end{array}$ & $\begin{array}{l}\text { Folha de São Paulo } \\
\text { e Portal Vermelho }\end{array}$ \\
\hline Outubro 2008 & Sertãozinho, SP & Diversas & 10000 & $\begin{array}{l}\text { Reajuste, condições de } \\
\text { alojamento }\end{array}$ & Sem informação & Blog do Sakamoto \\
\hline Novembro 2008 & Caiuá, SP & DECASA & 500 & $\begin{array}{l}\text { Descumprimento de } \\
\text { acordo coletivo }\end{array}$ & Sem informação & $\begin{array}{l}\text { Portal Mídia } \\
\text { Independente }\end{array}$ \\
\hline Dezembro 2008 & Andradina, SP & Cosan & 300 & $\begin{array}{l}\text { Descumprimento de } \\
\text { acordo coletivo }\end{array}$ & Sem informação & $\begin{array}{l}\text { O Estado de } \\
\text { São Paulo }\end{array}$ \\
\hline Agosto 2009 & Sertãozinho, SP & Aralco & 600 & Reajuste & Sem informação & Folha de São Paulo \\
\hline Outubro 2009 & Araraquara, SP & Tamoio & 300 & Reajuste de $100 \%$ & Sem informação & Portal da CTB \\
\hline Fevereiro 2010 & Florestópolis, PR & Cofercatu & 1300 & Atraso salarial & $\begin{array}{l}\text { Dispensa dos } \\
\text { trabalhadores }\end{array}$ & Gazeta do Povo \\
\hline Agosto 2011 & $\begin{array}{l}\text { General Salgado } \\
\text { SP }\end{array}$ & Aralco & 300 & Reajuste do metro cortado & Sem informação & TV TEM \\
\hline Setembro 2011 & Itapetininga, SP & $\begin{array}{l}\text { Vista } \\
\text { Alegre }\end{array}$ & 400 & $\begin{array}{l}\text { Reajuste salarial e melhores } \\
\text { condições de alojamento }\end{array}$ & $\begin{array}{l}\text { Demissão dos } \\
\text { trabalhadores }\end{array}$ & $\begin{array}{l}\text { Entrevistas dos } \\
\text { autores }\end{array}$ \\
\hline Junho 2012 & $\begin{array}{l}\text { Marabá Paulista, } \\
\text { SP }\end{array}$ & DECASA & 700 & $\begin{array}{l}\text { Recolhimento do FGTS } \\
\text { e INSS }\end{array}$ & Sem informação & Portal Independente \\
\hline Janeiro 2013 & $\begin{array}{l}\text { Marabá Paulista, } \\
\text { SP }\end{array}$ & DECASA & 300 & Salário & Sem informação & Portal Prudentino \\
\hline
\end{tabular}

Fontes: Pesquisa de Campo, 2013.

gados Rurais Assalariados do Estado de São Paulo (Feraesp), ao descrever o grau de conturbação que marcou a safra 2007/2008 na região de Ribeirão Preto (SP), umas das principais áreas canavieiras do país. A referência é à histórica greve dos cortadores de cana ocorrida no município de Guariba, na mesma região, em 1984, e que reuniu cerca de cinco mil trabalhadores na luta por melhores salários. De acordo com Aguiar, 28 anos depois, em outubro de 2008, pelo menos 10 mil cortadores cruzaram os braços em diferentes cidades paulistas, como Colômbia, Viradouro, Terra Roxa, Morro Agudo, Pontal e Sertãozinho. Mas o movimento não se unificou e ficou isolado em cada usina. Assim como na época de Guariba, as greves não surgiram de uma articulação sindical centralizada, mas foram fruto da insatisfação comum com a remuneração oferecida pelas empresas. Após as greves, muitas companhias aumentaram o piso salarial e o valor pago pela tonelada da cana, mas permaneceu um hábito que relembra o passado: a perseguição aos chamados "cabeças da greve" - trabalhadores considerados "mais conscientes" e que possuem influência sobre os outros. (Sakamoto, 2008, p. 1)
Como indica o relato, as greves realizadas em 2008 foram motivadas pela insatisfação dos trabalhadores por questões salariais, mas não surgiram de uma articulação conduzida por organizações de representação política dos trabalhadores, como os sindicatos, pois constituíram uma ação coletiva iniciada de forma autônoma e espontânea pelos trabalhadores, embora outros atores pudessem se incorporar no decorrer da greve - como liderança sindical, Ministério do Trabalho ou Ministério Público do Trabalho. Além das reivindicações por melhoria de salário, existem também outras queixas sobre as condições dos alojamentos ${ }^{6} \mathrm{e}$ a ali-

${ }^{6}$ De acordo com as informações dos trabalhadores com quem conversamos e que também foram entrevistados para o documentário O CONFLITO, dirigido pelo Prof. José Roberto Novaes da UFRJ, as condições da fonte de água que a usina disponibilizava para o uso dos trabalhadores eram péssimas. A fonte de água estava localizada próxima do alojamento, em céu aberto e era contaminada por dejetos de cozinha. 
mentação, como também veremos no caso da Usina Vista Alegre, a ser analisada na parte seguinte. Há também casos de denúncia de situações de humilhações a que são submetidos os trabalhadores, como é relatado nesta notícia:

Denúncias de desrespeito e humilhações: Os trabalhadores denunciaram este e outros fatos à Feraesp, ontem, em Sertãozinho, e as medidas judiciais cabíveis serão encaminhadas”, disse a assessora jurídica da entidade, a advogada Olga Melzi. A advogada diz que denúncias "chegam às dezenas, sendo que em todas as empresas os gatos estão dispensando tratamento desumano aos trabalhadores que não suportam mais as humilhações (Uita, 2008, p. 1).

O salário por produção é a forma de remuneração que predomina entre os cortadores de cana-de-açúcar. O trabalhador recebe pela quantidade de cana cortada em cada dia. A medição da quantidade de cana cortada é realizada da seguinte maneira: cada cortador tem um trecho de cinco ruas (fileiras) de cana para cortar. O fiscal da usina mede a quantidade de metros que o trabalhador cortou durante o dia. Há diferentes classificações de cana-de-açúcar, a partir do tamanho apresentado pelas plantas e também da situação em que a lavoura se encontra: se está queimada ou se está com a palha; se for cana de primeiro corte, ou de segundo corte. Em cada situação, é estabelecido um preço diferente, pois, se a cana estiver em pé, em boas condições, e tiver um peso bom, o cortador conseguirá derrubar mais toneladas por dia; se a cana estiver enrolada e apresentar pouco peso, o cortador irá derrubar menos toneladas, por vezes utilizando o mesmo esforço físico. Há casos de equiparação do preço: se a cana estiver “feia”, paga-se um pouco mais. Há casos em que não há equiparação. A discordância sobre o preço da cana é um dos grandes fatores que causam greves. ${ }^{7}$ A perseguição aos chamados "cabeças de greve" é uma tática constantemente utilizada pelas usinas, que dificilmente recontratam os trabalhadores que tomam a frente das paralisações. O trabalha-

${ }^{7}$ Sobre pagamento de trabalhadores, indica-se o trabalho de Guanais (2010). dor entrevistado neste artigo, que foi um dos líderes da greve, não foi mais contratado nas safras de 2012 e 2013 pelas usinas do Estado de São Paulo.

A partir do movimento espontâneo dos trabalhadores, outros atores sociais são mobilizados, como os sindicatos, o Ministério Público do Trabalho, o Ministério de Trabalho e Emprego. Das 14 greves que temos notícias, apenas uma não teve a presença do sindicato: a greve na Usina Boa Vista em Pontal, que acabou com três lideres presos e seis pessoas feridas no confronto com a polícia (Portal Vermelho, 2008).

\section{O CASO DA GREVE DA USINA VIS- TA ALEGRE}

Em março de 2011, 400 trabalhadores partiram do Sertão da Paraíba e do Sertão do Ceará para trabalhar na colheita da cana-de-açúcar, na Usina Vista Alegre, no município de Itapetininga, Estado de São Paulo. A seleção dos trabalhadores foi realizada por um turmeiro, o J.G, que é funcionário da Usina. O turmeiro atua como mediador em todos os tempos e espaços que envolvem a relação dos trabalhadores migrantes com a usina, tais como em processo de seleção, exames médicos, contratação, acerto de contas, gestão do trabalho no cotidiano dos canaviais e vigilância nos alojamentos. É também o interlocutor das reclamações e demandas dos trabalhadores, assumindo, não raras vezes, a mediação dos conflitos. Os 400 trabalhadores foram distribuídos em 10 turmas de 40 pessoas cada. A grande maioria realizava a função de cortador de cana, porém, havia também cozinheiras, fiscais e zeladores dos alojamentos. Para muitos desses trabalhadores, não era a primeira vez que faziam esse trajeto. Todos os anos, algum "turmeiro" organizava os trabalhadores interessados em "tirar uma safra” e, no mês de março, eles seguiam em ônibus para o estado de São Paulo.

Ao serem contratados, os trabalhadores 
são informados do preço da cana por tonelada, quais são as exigências da usina em termos de produtividade e de qualidade da produção, das boas condições de alojamento e alimentação e assistência médica em caso de doença ou acidente de trabalho. O processo de contratação é realizado ainda nas localidades de origem dos trabalhadores, na região Nordeste do Brasil, onde são explicados os termos do contrato. No entanto, a realidade vivenciada foi bem diferente da promessa, como é relatado por J.L, migrante do município do Barro, Ceará.

É que a (Usina) Vista Alegre, quando ela veio contratar o pessoal aqui, eles prometeram muito pra gente, né. Uma boa alimentação, boa estadia, alojamento, assistência médica. Só que quando a gente chegou lá que foi trabalhar, aí a gente viu que as coisas não eram aquilo que eles prometeram. Começou ser diferente, tinha muitas coisas que começou a vir com abuso, da parte deles. Dai aquilo veio gerar um transtorno e a greve no final. (J.L, cortador de cana de Barro (CE), em entrevista realizada em fevereiro de 2013).

O relato de J.L indica que o prometido aos trabalhadores não foi cumprido pela usina. Em agosto de 2011, decidiram entrar em greve pelo fato de observarem que o volume de trabalho daquele mês era o mesmo dos meses anteriores, porém o salário auferido foi menor. Isso ocorreu porque o preço da cana utilizado pela usina para o cálculo do salário dos trabalhadores era menor do que o acordado quando da contratação. O trabalhador C.P, nos explica:

Maciel - a gente também queria saber como foi essa paralisação, porque teve essa paralisação?

Entrevistado - Preço de cana. O preço da cana tava muito baixo. Que quando foi pra gente sair daqui eles prometeram que não ia ter preço de cana de menos de 10 centavos. Por metro né, você entende. E a gente tava cortando e eles estavam pagando de 8 e 9 nove centavos muitas canas. (C.P, cortador de cana de São José de Piranhas, entrevista realizada em março de 2012)

$\mathrm{O}$ argumento de que o preço de cana fora o motivo inicial da paralisação também é apontado pelo trabalhador M.B, que explica como se iniciou o protesto:
Maciel - Ai teve esse lance. O pessoal atrasou o pagamento?

Entrevistado - Não! Foi assim: os pagamentos estavam vindo bom. Aí começou vim uns preço de cana errado. Cana que a gente cortava de 40 centavos, estava vindo de 20 centavos. Aí os caras foi e pararam. Aí os pagamentos começaram vir baixo. No meu salário mesmo, veio 400 contos a menos. Aí uma turma parou aí disse: amanhã ninguém vai pra roça e não vai mesmo não. Foram atrás da Carlita. Nossa turma mesmo tava todo mundo pronto pra trabalhar na roça, o problema foi os outros. Ai a gente não ia brigar com os companheiros daqui, né. (M.B, cortador de cana de São José de Piranhas, entrevista realizada em março de 2012).

Nesse relato, é possível perceber que o movimento da greve começou a partir da iniciativa de um grupo de trabalhadores e os demais aderiram seja por solidariedade ou porque apoiavam a ação. Entrevistamos um trabalhador contrário à greve, que afirmou “... os meninos acharam o pagamento ruim né, a gente parou” (G. M, zelador, de São José de Piranhas, PB, entrevista realizada em março de 2012). No desenvolvimento da greve, há posicionamentos diferentes dos trabalhadores. Entrevistamos A. R. S. que disse:

[...] a gente pegou a roupa pra trabalhar e ficava uns cara lá dizendo 'isso é um lote de babão’. Aí um monte de cara ia inventar de falar alguma coisa. É melhor ficar quieto [...]. Eles diziam assim: ‘vai tirar essa roupa, lote de babão, fica babando os homens aí, não sei o que[...]'. (A. R. S, cortador de cana de São José de Piranhas, entrevista realizada em março de 2012).

Esse fragmento mostra que uma tática utilizada pelos que inicialmente apoiaram a greve foi a classificação e nomeação dos que continuaram trabalhando como "lote de babão", demonstrando que eles estavam do lado do patrão. A expressão "vai tirar essa roupa, lote de babão" é um apelo para o trabalhador mudar sua posição e se juntar ao bloco dos que estavam apoiando a greve. Assim, ele estaria sendo leal a seus colegas de trabalho e demonstrando seu pertencimento à sua classe, como trabalhador. 
O depoimento desse trabalhador demonstra também que sua posição era desprezada pelos que aderiram à greve. Um dos líderes da greve, J. L, conta como se iniciou o movimento:

Maciel - Ai vocês decidiram parar?
Entrevistado - É, a gente decidiu parar. Era muita
coisa que gerou um problema pra gente. Porque a
gente tinha maus trato, comida ruim, assistência de
saúde deles era péssima e a cana totalmente dife-
rente o preço. E a gente tirou um pagamento lá que
todos nós ficamos satisfeito, se eu não me engano
foi o pagamento do mês de julho trabalhado. Aí, no
pagamento do mês de agosto, deu quebra de 50\%
em todos, no geral. Isso a gente tinha 400 e pou-
cas pessoas lá no pessoal do corte. Isso causou uma
revolta muito grande no pessoal. Porque uma dife-
rença tão grande assim: se, em um mês, se trabalha
26 dias e você tira x e, no outro mês, os mesmos 26
dias trabalhados você recebe uma diferença de $50 \%$.
E a gente chamou eles até pra negociar um preço da
cana. (J. L, cortador de cana de Barro, CE, entrevista
realizada em fevereiro de 2013).

A greve foi precedida de tentativas de negociação com o chefe imediato - o turmeiro - e com o funcionário do Setor de Recursos Humanos, que não foram eficazes, não avançando para o atendimento da reivindicação dos trabalhadores. A primeira negociação foi com o arregimentador, o mediador paulista responsável pela contratação dos trabalhadores nordestinos. Por mais que a terceirização de corte de cana seja um ato combatido pelas instituições reguladoras do Estado, o sistema de controle do trabalho fundamenta-se em agentes diretos, como os arregimentadores e turmeiros, cuja vigilância sobre os corpos, espaços e linguagem dos trabalhos é diuturna. Na ocorrência do conflito, o primeiro a buscar o controle dos trabalhadores é esse agente, como nos explica J. L:

Maciel - E o J.G?

Entrevistado - O J.G (o arregimentador) também! Por que eles lá serviam como porta voz. Daí quando começou a apertar a coisa mesmo, o pessoal da usina nem vinha lá, quem vinha era o J. G. A gente fazia proposta e mandava pro J. G, dizia: ajeite com o pessoal que o pagamento não é esse. Teve pessoas lá que chegou a tirar até dois mil de pagamento 2 mil e pouco e depois caiu pra mil, quem tirou mil tirou 500. Então, não tinha condições o pagamento como foi feito. Aí eles bateram o pé e disse que o pagamento é esse aí, quem quiser trabalhar trabalha, quem não quiser peça as contas. Aí foi onde gerou toda a revolta, começaram a parar, aí parou todo mundo. (J. L, cortador de cana de Barro, CE, em entrevista realizada em fevereiro de 2013).

$\mathrm{O}$ arregimentador foi o interlocutor durante todo o tempo, sobretudo nos momentos mais críticos. A estratégia inicial foi o diálogo com o turmeiro, chefe imediato e de maior proximidade, na expectativa de que ele seria sensível à reclamação dos trabalhadores e encaminharia alguma solução junto aos chefes superiores da usina, como os funcionários do Setor de Recursos Humanos. No entanto, a mediação não resultou em uma possibilidade de negociação, mas numa tentativa de fazer os trabalhadores se calarem, através da ameaça de demissão caso não aceitassem o valor do pagamento.

Os trabalhadores não se intimidaram e decidiram parar como uma estratégia para serem ouvidos e conquistarem seus pleitos. Nesse momento, o setor de Recursos Humanos, veio dialogar diretamente com os trabalhadores, como nos relata J. L: Maciel - Aí parou o primeiro dia e eles continuaram
negociando com vocês e o J.G?
Entrevistado -É, a gente parou no primeiro dia, aí apa-
receu gente da usina. Mas como a gente já tava ciente
de que eles não iam ajeitar o pagamento do pessoal, já
fomos procurar o pessoal do ministério. E nisso veio
um rapaz da usina lá que era diretor de recursos hu-
manos e representava a usina e que gerenciava lá den-
tro. E já veio com uma conversa totalmente diferente.
A ideia deles é que a gente fosse trabalhar, mas só que
a gente poderia até voltar a trabalhar, mas só que a gen-
te queria que eles ajeitasse o nosso pagamento. Mas aí
eles falavam que o pagamento era aquele mesmo. (J. L,
cortador de cana de Barro, CE, em entrevista realizada
em fevereiro de 2013).
Nesse processo, J. L detalha como se
dava a organização. Alguns trabalhadores já
haviam participado de outras greves e também
conheciam pessoas do sindicato, como a sin-
dicalista Carlita, da Diretoria do Sindicato dos
empregados rurais de Cosmópolis, que foi con- 
vocada para auxiliar na paralisação.

Embora tenham desenvolvido uma ação dentro da ordem estabelecida, ou seja, sem cruzar os braços, não foram ouvidos pelos mediadores da usina. A emergência da greve foi compreendida como uma estratégia necessária para expressar seu sentimento de indignação e lutar contra o roubo na produção. A greve, termo dos trabalhadores para essa ação coletiva, é uma “ação espontânea”, ou seja, resultado dos próprios trabalhadores, sem mediação de lideranças do sindicato ou de outros movimentos sociais. Ao entrevistarmos a Presidente do Sindicato de Cosmópolis, que foi chamada para dar apoio e orientação aos trabalhadores, ela nos explica que é uma paralisação, e não propriamente greve:

A gente chama paralisação porque a greve é mais intensa, ela pode ser de 10 a 15 dias; agora as paralisações ocorrem 3, 4 ou 5 dias e já param. Então, não considero isso como greve, é uma paralisação. Geralmente ela ocorre no pé do eito, no local de trabalho mesmo, ela permanece localizada, o pessoal vai de manhã, fica lá, quando são migrantes, fica no alojamento, mas não saem para a cidade, paralisando tudo. (Entrevista realizada em 29 de julho de 2013).

Para a sindicalista, o termo é paralisação e, para os trabalhadores, é greve. Adotamos a nomeação dos trabalhadores - greve. Embo• ra sem a direção de lideranças do sindicato ou

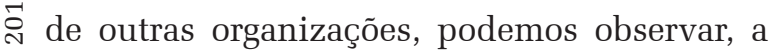
partir dos relatos dos grevistas, que havia uma สี่ organização, como nos explica J. L:

Maciel - Aí vocês tinham uma equipe que coordenava os trabalhadores?

Entrevistado - Não, era cada um por si. Como o problema era com todos e como a gente vai em equipe, então a gente tem muitos conhecidos e sempre se junta. E como a gente vai trabalhar todos os anos, nós sabemos a capacidade da gente. E vimos que não tinha condições da gente trabalhar ganhando bem menos do que o esperado. Então, foi onde começou formar aqueles grupos de pessoas que não concordava com o pagamento e desejavam parar. E sempre tinha uns que era pela usina, mesmo sabendo que a usina estava errada, eles querem correr junto à usina e continuar trabalhando. Daí o outro grupo já dizia que tinha que parar todo mundo. Porque se um vai trabalhar, é o que eles querem; daí, ao invés de corrigir o erro que estão cometendo, eles vão querer punir, mesmo estando errado. Então eles vão dizer que trabalho tem, mas o trabalhador é que não quer trabalhar, então eles vão punir. E como eles vão punir? Vão botar uma falta lá, um gancho, que eles chamam de gancho, eles cortam o remunerado da semana, vem os dias em que você não ganha nada, cortam cesta básica, daí se você for trabalhar você vai ganhar em torno de 20, 30 reais num dia. Aí se você falta um dia, eles fazem um desconto que, quando chega o final do mês, fica em torno de 200, 250 a 300 reais; é uma coisa que é fora do comum. (J. L, cortador de cana de Barro, CE, em entrevista realizada em fevereiro de 2013).

Há cinco elementos importantes nessa narrativa. Primeiro, há o fato de os trabalhadores serem "conhecidos", ou seja, são parentes, amigos, vizinhos cujos laços sociais remetem às suas localidades de origem, pois são dos mesmos sítios, bairros ou municípios no Sertão da Paraíba e do Ceará. Isso constitui uma base social de confiança e de reciprocidades para a ação coletiva. Em segundo lugar, eles não são "marinheiros de primeira viagem", mas experientes nas usinas e conscientes de sua "capacidade", tanto produtiva quanto política. Sabem da sua importância para as usinas: afinal, sem cortador de cana, a colheita e a produção industrial podem ficar comprometidas.

Em terceiro, o comentário sobre a greve circulava entre os trabalhadores, gerando posições favoráveis e contrárias. O quarto elemento diz respeito ao fato de a estratégia organizativa inicial ser a de formar grupos de trabalhadores que eram a favor da greve e que estavam assumindo o risco de levar "gancho". Finalmente, o quinto elemento é o fato de a motivação para a greve não ser propriamente uma reivindicação de maior salário, mas se fundamentar numa noção de justiça, ou seja, de que o salário era menor do que a produção em toneladas de cana cortada.

Como fonte de nossa pesquisa, utilizamos algumas cenas do Documentário O Conflito, dirigido por José Roberto Novaes, filmado 
durante a greve. O professor José Roberto Novaes, ao ser informado da greve pelo Sindicato de Cosmópolis, foi para Itapetininga, a fim de registrar alguns momentos da mobilização dos trabalhadores migrantes, o que, posteriormente, foi utilizado na composição de seu documentário. Utilizamos as cenas que se situam entre décimo terceiro e décimo quarto minuto do filme, em que a sindicalista Carlita discute com o arregimentador J. G. Os dois estão sobre um barranco, e mais abaixo, no pátio, um grupo de mais de 50 trabalhadores assistem ao diálogo.

\section{J. G fala: “- Eu não sou ladrão”.}

Em seguida, um sindicalista do sindicato de Cosmópolis, César, fala para os trabalhadores: "O J. G tá dizendo que não é ladrão, e a gente quer acreditar. Mas olhando os holerites de vocês, e vendo que sendo cana crua, cana queimada, cana de primeiro corte, cana de segundo corte, todas as canas o preço é só dez centavos, não dá pra chamar isso de outra coisa”, referindo-se ao fato de que isso seria uma forma de roubo da Usina e do arregimentador. ${ }^{8}$

O J. G. e os trabalhadores gritam e aplaudem o sindicalista.

A cena demonstra os atores em movimento. O representante da usina buscando se justificar, os sindicalistas buscando defender a greve dos trabalhadores e a tese de que houve roubo no pagamento da cana. Os trabalhadores aplaudem o discurso do sindicalista, demonstrando a sua aprovação.

Os trabalhadores migrantes reivindicavam um pagamento justo: "Vímos que não tinha condições da gente trabalhar ganhando bem menos do que o esperado" indica uma percepção da diferença entre o preço prometido pela usina e a quantidade produzida. Assim, não há propriamente uma reivindicação

${ }^{8} \mathrm{O}$ documentário também exibe as condições dos alojamentos, os colchões e travesseiros estragados, as péssimas condições dos ônibus que transportam os trabalhadores para os canaviais e também o reservatório de água que abastece o alojamento, que fica localizado logo abaixo de uma fossa; a poça de água se apresenta com uma camada de sujeira na superfície, indicando, para qualquer leigo, que não está em condições para o uso humano. por maior salário, mas apenas do cumprimento do que fora acordado, compreendido como preço justo. Com base na noção de economia moral de James Scott (1976), entendemos que a noção de justiça não é um a priori na orientação da conduta e percepção dos grupos sociais, mas é construída em situações específicas de dominação.

No que diz respeito às relações de exploração no trabalho, o julgamento varia numa escala gradativa do que é concebido como justo e legítimo. Se os grupos que estão em situação de dominados avaliam uma relação de exploração como uma 'troca equilibrada", é porque ela responde às suas expectativas. Scott propõe uma diferença entre frustração e indignação, para explicar a motivação das formas de resistência, seja do discurso oculto ou no discurso público, como é o caso da greve. Entendemos que a greve representa uma passagem de um discurso oculto para um discurso público, porque ela explicita, torna visível, de modo coletivo e com enfrentamento dos detentores do poder, o sentimento do "roubo". ${ }^{10}$ No início da paralisação, não procuraram o sindicato local nem outro agente ou instituição no município, mas telefonaram para a Presidente do Sindicato de Cosmópolis, a Senhora Carlita, que tem uma boa imagem entre os trabalhadores migrantes pela sua atuação política na defesa dos trabalhadores.

Em entrevista que realizamos com Carlita, ela conta como foi o contato:

Eu tava aqui no sindicato e ligaram, mas eu não

${ }^{9}$ De acordo com Scott (1976, p. 174), “[...] the idea of a balance of reciprocity or a balance or exchange implies a continuum of possible links, ranging all the way from equality of exchange to unreciprocal relationships of pure coercion".

${ }^{10}$ Ferrante, na análise das greves dos boias-frias da década de 1980 em São Paulo, esboça uma compreensão da relação entre práticas do discurso oculto e publico, embora, nos textos, a autora não utilize a terminologia conceitual de James Scott: "Importantes descobertas se fizeram presentes nesse movimento. Pequenas lutas, movimentações que ocorriam de modo quase silencioso, traços distintivos de práticas sindicais passaram a exigir mudanças do entendimento da realidade, que não ocorreram magicamente. Seu passo a passo registra um duplo movimento: de um lado, minhas buscas de fazer visível o que se ocultou, de ouvir, através de registros de arquivos, dos árduos processos trabalhistas, as falas dos atores, de entender a dominação não como um pacote homogêneo e castrador, mas um conjunto de respostas igualmente modificadas na espreita de sinais de resistência," (Ferrante, 1989/90, p.75). 
podia ir naquele dia. Aí depois, passou uns 4 dias, eles vieram aqui; veio 2 ou 3 trabalhadores e eu combinei de ir no dia seguinte. Eles disseram que estavam parados. Aí fomos e fizemos um trabalho legal, porque eu falo assim: esse povo que consegue paralisar e botar a cara de fora são guerreiros na atual conjuntura. Eu valorizei muito o que eles fizeram (Entrevista em 29 de julho de 2013).

A Usina Vista Alegre não está na base do Sindicato de Cosmópolis. Por esse motivo, Carlita consultou o Presidente da Federação dos Empregados Rurais do Estado de São Paulo (FERAESP), Sr. Helio Neves, que concordou que ela acompanhasse os trabalhadores. A Sra. Carlita chamou o Ministério do Trabalho e a Procuradoria para ajudar na orientação aos trabalhadores. Os auditores do Ministério do Trabalho e o procurador do Trabalho de Sorocaba foram acompanhar a mobilização e fiscalizar as condições de trabalho e o alojamento. Também entrou em cena a advogada e uma funcionária do escritório da FERAESP. Nos relatos dos trabalhadores, as presenças dos quatro atores aparecem compondo o cenário dos mediadores:

Procuramos o ministério, lá, o pessoal que foram procurar o ministério lá não foram bem recebido. Já apareceu o cara da usina, já foi lá conversar com o pessoal do ministério dizer que era o pessoal que tava se recusando a ir trabalhar. Daí o pessoal já foi procurar o sindicato dos trabalhadores, que é uma área que fica lá em Cosmópolis. Pegar a Doutora Carlita e, assim, lá ela recebia o pessoal bem e se comprometeu em resolver os problemas da gente. É tanto que ela veio aparecer lá uns dois dias depois; quando ela chegou lá foi que fechou mesmo, que ela disse: não, aqui tá tudo errado e não pode ser dessa forma, ninguém vai trabalhar e começou a falar o que a usina tinha que acertar com a gente. E, na usinan botaram o pé também e vamos partir pra reunião. Depois começou a embolar e passar os dias. E o sindicato com a usina começaram a negociar. Aí veio aparecer o ministério do trabalho, aí apareceu outro pessoal que é da FERAESP de Itapetininga e começaram negociar (J. L, cortador de cana de Barro, CE, em entrevista realizada em fevereiro de 2013).

O documentário "O Conflito", dirigido pelo Professor José Roberto Novaes, retrata a greve dos cortadores de cana da Usina Vista
Alegre. Novaes foi informado da greve pelos sindicalistas de Cosmópolis e, então, foi até Itapetininga com um cinegrafista da Universidade Estadual de Campinas (Unicamp), para entrevistar os trabalhadores e fazer imagens das mobilizações. No filme, também são incluídas imagens captadas pelos trabalhadores, através de seus aparelhos celulares. No documentário, há entrevistas dos trabalhadores, explicando os motivos da greve. A motivação inicial foi o "roubo", ou seja, o pagamento inferior à produção dos trabalhadores. Mas, no processo mesmo da paralisação, os trabalhadores reivindicaram finalizar o contrato de trabalho com todos os direitos e o direito de retornar às suas casas. J. L nos explica que o desejo de ir embora é porque eles têm medo de que as condições de exploração continuem ou de represálias dos chefes. Mas entendemos também que deixar a usina no auge da safra também se expressa como uma ação de resistência, como uma arma dos fracos contra os fortes nos termos propostos por Scott (1990).

O relato abaixo nos dá elementos para compreender o sentimento e a percepção dos trabalhadores:

Eu que estava na frente junto com o pessoal achei que aquilo ia ser resolvido que eles iam acertar os pagamentos e diante daquilo ali tinha muitos que estavam revoltados e não queria mais trabalhar. Porque eles achavam que, se fossem trabalhar, o pessoal da usina ia continuar fazendo da mesma forma. E geralmente é assim: quando um desanima quer vir embora, aí vai um atrás do outro. Porque o pessoal que vai para o corte de cana é mais em família, vai um, aí leva um irmão, um primo, cunhado, tio, sobrinho. Aí quando chega um e diz: não, eu não vou embora pra deixar meu irmão sofrendo aqui. Aí o outro diz: Ah! o meu tio vai, eu vou também. Aí ficou aquela coisa, nós vamos embora. Eles não queriam negociar pra gente vir embora, eles queriam negociar pra gente voltar a trabalhar. A intenção de Carlita era essa (J. L, cortador de cana de Barro, CE, em entrevista realizada em fevereiro de 2013).

Os trabalhadores já tinham uma clareza do que queriam: eles queriam uma solução rápida. Mas o tempo dos outros atores - sindi- 
calistas, Ministério e Procuradoria do Trabalho - é outro. A greve durou 17 dias.

Só que ninguém era obrigado ficar trabalhando forçado. Porque se fosse pra gente ficar lá, a gente ia ficar forçado. Porque trabalhar sem intenção? Trabalho, por pior que seja, a pessoa tem que trabalhar com gosto, com prazer, sentir vontade de fazer. Se você não tiver vontade, então não adianta. Porque você tá trabalhando pensando que o cara está lhe roubando, aí diz eu não fico e não fica mesmo... E, lá no começo, eu dizia: não eles vão resolver, né... Eles estão agindo de boa forma e vão resolver essa questão, mas só que, com o decorrer do tempo, eu mesmo vim ver que eles estavam trabalhando individual. O ministério queria trabalhar de uma forma, o sindicato de outra forma e a FERAESP também. Cada um queria fazer do seu jeito, porque era uma questão muito grande. O pessoal, entre cortador, zelador, cozinheiro, era em torno de 430 pessoas. Então aquele que conseguisse resolver a questão, seja FERAESP, ministério ou sindicato, ele ia crescer o nome na região; por isso que eles trabalham individual. Porque eles deveriam trabalhar em conjunto, a condição de trabalho aqui está difícil e vamos ajeitar. Aí, sim, teria sido muito fácil e tinha conseguido resolver de uma hora pra outra. Mas o sindicato trabalha de uma forma, a FERAESP de outra, aí fica difícil. E acabou que a gente ficamos 17 dias de sofrimento. As cozinheiras foram dispensadas, as cozinhas foram fechadas. E também o dinheiro das cozinheiras é muito pouco, a comida é péssima. Que também as cozinheiras não tinha tanta culpa (J. L, cortador de cana de Barro, CE, em entrevista realizada em fevereiro de 2013).

O trabalhador J.L relata o momento em que ele, como representante e líder da greve, foi ao escritório do Ministério do Trabalho, juntamente com um integrante da FERAESP:

Aí quando eu cheguei lá com o Ciro da FERAESP, eles começaram a conversar, como já fossem conhecidos há muito tempo. Ele disse: "É Ciro, esse pessoal aí, a usina depositou tanta confiança neles. Foram lá no nordeste dar serviço pra eles aqui, eles foram logo com desordem dentro da usina, queriam botar fogo, aí fizeram aí essa muvuca toda e terminou nisso aí. Agora eles estão aí nessa canseira”. Aí eu disse: "Dr. Celso, eu não vou dizer que o senhor está mentindo porque é uma falta de respeito com a sua pessoa, mas eu acho que o senhor está muito equivocado. Eu estive à frente de todo trabalho dentro da usina, representando o pessoal, e lá não houve essa manifestação desse pessoal não querer atirar fogo em alojamento, nem em ônibus não. Muito pelo contrário, a parte que a gente mais se preocupava era em não danificar a usina. Porque a gente tem certeza que, se fizesse isso, seria crime, e a gente ia ter que arcar com isso aí depois. Então a gente não queria danificar material de ninguém, a gente queria buscar os nossos direitos. Aí eles desconversou e ficou em nada. Aí foi onde eu tirei a conclusão de que eles estavam fazendo cada um por si. Porque era uma causa muito grande: quem fizesse ia ganhar respeito com isso aí. Agora, se a FERAESP deixou a desejar, foi quem fez mais por nós. Pelo menos eles acompanharam a gente até na hora de viajar; a doutora Adriana esteve presente com a gente lá e mais uma auxiliar dela. Pra mim foi uma ótima pessoa; apesar do que vem acontecendo, até ali foi uma ótima pessoa (J. L, cortador de cana de Barro, CE, em entrevista realizada em fevereiro de 2013).

Esse fragmento de fala evidencia o jogo dos atores no cenário da greve dos trabalhadores migrantes. Observamos certa crítica à atuação do agente do Ministério do Trabalho e, embora se apontem falhas dos agentes da FERAESP, afirma-se que eles efetivamente defenderam os trabalhadores.

É importante observar que a Presidente do Sindicato de Cosmópolis, a Sra. Carlita, que foi acionada no início da greve devido ao respeito e à confiança que os trabalhadores migrantes lhe tinham, desapareceu de cena. De fato, ela teve um papel importante em mobilizar todos os atores, embora, na fase de negociação com a usina para os acertos finais, a FERAESP, como instituição oficial representante dos empregados rurais do Estado de São Paulo, assumiu a liderança, dispensando a presença de Carlita. É nesse jogo de disputa entre atores que os representantes da FERAESP ganham mais legitimidade entre os trabalhadores migrantes.

Esse jogo entre os atores e a busca por legitimidade institucional são captados na frase de J. L: “[...] aí foi onde eu tirei a conclusão de que eles estavam fazendo cada um por si. Porque era uma causa muito grande quem fizesse ia ganhar respeito com isso aí".

O documentário O Conflito mostra que, 
no diálogo entre a Usina, a FERAESP e os trabalhadores, chegou-se ao acordo de demissão dos trabalhadores com pagamento das indenizações trabalhistas e também com acerto dos pagamentos atrasados após 17 dias de paralisação. Os trabalhadores optaram pela demissão, pois a maioria queria voltar para suas localidades rurais no Estado da Paraíba e do Ceará, na região Nordeste do Brasil. A Usina financiou os ônibus que os levariam para suas casas e também pagou uma parte do acerto de contas em São Paulo, e a outra parte alguns meses após, na sede Sindicato dos Trabalhadores Rurais de São José de Piranhas (PB). As últimas cenas do documentário exibem o momento em que os sindicalistas e um dos líderes da greve, o J. L., organizam os encaminhamentos, após o resultado positivo das negociações, em que os trabalhadores alcançaram seu pleito, ou seja, ser demitidos e recuperar os pagamentos. Um trabalhador começa a gritar e os demais, em coro, seguem dizendo: "O povo, unido, jamais será vencido".

\section{CONSIDERAÇÕES FINAIS}

O desfecho da greve resultou na conquista do objetivo dos trabalhadores, que era iे suas casas. Assim, tanto mostraram sua força política, colocando a usina em situação frágil ฐึ. perante o Ministério do Trabalho e o Ministéro rio Público do Trabalho, quanto revelaram que são capazes de mobilização e ação coletiva de forma autônoma e espontânea. Duas questões i merecem reflexão: os trabalhadores teriam \& perdido a autonomia e outros atores ganhado จิ espaço político durante o desenvolvimento da greve? Podemos caracterizar esse movimento como espontâneo diferenciando-se de um movimento conduzido pelo sindicato?

Em relação à autonomia, entendemos que não há propriamente perda, mas ela vai assumindo diferentes significados nos tempos e espaços da mobilização. Se a negociação final foi marcada pela negociação entre FERAESP e a usina, isso não significa uma perda de autonomia para os trabalhadores, já que resulta de uma ação coletiva promovida pelos trabalhadores, e o fato de conquistarem sua reivindicação demonstra sua capacidade de liderança. As greves dos "boias-frias", que marcaram a década de 1980, também foram marcadas por ações dos trabalhadores não conduzidas pelas lideranças sindicais. Há diversas visões sobre a relação entre esses atores, ${ }^{11}$ e concordamos com a perspectiva de Ferrante (1988; 1989/90; 1994) em seus textos sobre o ciclo de greves nas usinas do Estado de São Paulo na década de 1980. Fundamentada em Sader \& Paoli (1986), a autora questiona algumas polaridades, como espontâneo e organizado, e defende a ideia de atores múltiplos.

\begin{abstract}
"Em cada uma das lutas, em cada acontecimento coletivo, os pesquisadores tendem a ver atores integrais se fazendo sujeitos através de suas práticas. Não há mais qualificações bipolares tipo espontâneo/consciente, lutas econômicas/lutas políticas, práticas de fôlego curto/amplo, pelo menos como qualificações prévias. Não há também, portanto, hierarquias de importância política previamente estabelecidas. Não há mais 'consciência' atribuída e, portanto não há mais 'adequação’ ao oposto.” (20: 67). Com esta noção de atores múltiplos, integrais, cujo coletivo se forma pela articulação das diversas situações de dominação contestadas por seus movimentos, a avaliação do que "as classes populares são perde o sentido, para se transformar numa avaliação daquilo que os grupos estão enfrentando e estão sendo (Ferrante, 1989/90, p. 74)
\end{abstract}

Sobre a organização da greve, merece destaque que não chamaram a representação sindical do município de Itapetinga, demonstrando o não reconhecimento das lideranças desse sindicato; mas ao chamar uma liderança legitimada entre os trabalhadores, demonstraram o reconhecimento da representação sindical. Esses detalhes nos mostram que é temerária uma interpretação que contraponha

11 Sobre a discussão do sindicalismo no campo, faz-se necessário registrar a importante contribuição de Coletti (1998) que analisa o desenvolvimento dos sindicatos de trabalhadores rurais no estado de São Paulo. 
trabalhadores aos sindicatos, mas, antes, que suas ações políticas também podem ter desdobramentos sobre a representação e a ação sindical. Novamente concordamos com Ferrante (1989/90), quando evidencia a diferenciação dos sindicatos no período do ciclo de greves da década de 1980, que teve como marca a Greve de Guariba em 1984:

Afinal, o trabalho de resgatar invisibilidades nos trouxe como legado o desafio de trabalhar com uma montagem na qual se faz necessário caminhar analiticamente sobre as diferenças em termos de concepções, trajetórias e desfechos. Assim como se revelou nesse percurso a impossibilidade de discutir a ação dos boias-frias, homens-mulheres, em um bloco homogêneo, também os sindicatos, peças ausentes ou presentes no cenário das lutas, devem ser analisados em movimentos sob a ética de diferenciação de suas práticas (Ferrante, 1989/90, p. 81).

Trabalhadores rurais e sindicatos não necessariamente adotam as mesmas práticas na relação com o patronato, mesmo que partilhem de concepções ideológicas e políticas similares. As greves, como essa que analisamos, que são marcadas por uma mobilização espontânea dos trabalhadores, ou seja, que não são mediadas, inicialmente, pelos sindicatos, demonstram que tanto os trabalhadores quanto as lideranças sindicais são sujeitos com autonomia. Ambos são capazes de empreender ações políticas que mobilizem coletivamente a categoria. O caráter espontâneo da greve merece algumas problematizações. É espontâneo no sentido estrito de que o início da mobilização não foi conduzido por lideranças dos sindicatos, mas pelos próprios cortadores de cana. No entanto, isso não significa que não tenha havido organização e liderança. Podemos sintetizar a organização do movimento nas seguintes etapas: 1) os trabalhadores insatisfeitos com os pagamentos decidiram parar, motivados por um sentimento de injustiça 2) o primeiro ator a negociar com os trabalhadores foi o "turmeiro", ou seja, o agente que foi para as localidades de origem dos trabalhadores migrantes recrutar as turmas; 3) como o "turmeiro" não resolveu o problema, as negociações passaram a ser diretamente com o Setor de Recursos Humanos 4) buscou-se apoio na liderança do Sindicato de outra cidade, que é referência de luta dos trabalhadores da cana 5) essa sindicalista mobiliza o Ministério do Trabalho e a Procuradoria do Trabalho, 6) A FERAESP entra em cena, 7) Ocorre disputa entre os atores. Os sete momentos relatados demonstram que a paralisação partiu de uma mobilização "espontânea” dos trabalhadores migrantes. Os múltiplos atores que entraram em cena não apenas legitimaram a mobilização, mas também contribuíram para os trabalhadores expressarem sua luta contra o "roubo" praticado pela usina e seu sentimento de injustiça.

A experiência da greve também permitiu o surgimento de lideranças no próprio fazer-se da mobilização e da ação coletiva. J. L., que foi nosso principal narrador neste artigo, despontou como uma liderança importante, tornando-se o interlocutor no cenário dos atores.

Por fim, os trabalhadores optaram por voltar a seus municípios no sertão da Paraíba e do Ceará, e a usina pagou uma parte da dívida ainda em São Paulo e a outra parte alguns meses após, na sede Sindicato dos Trabalhadores Rurais de São José de Piranhas (PB).

Recebido para publicação em 29 de julho de 2014 Aceito em 13 de outubro de 2015

\section{REFERÊNCIAS}

ALMEIDA, Marco Antônio Ferreira. Diante do bagaço do Homem, onde está o Guardião do Interesse Público? O Ministério Público e a defesa dos direitos trabalhistas no agronegócio canavieiro. 2013. Dissertação (Mestrado em Ciências Sociais) - Programa de Pós-graduação em Ciências Sociais da Universidade Federal de Campina Grande.

ALVES, Francisco. Migração de trabalhadores rurais do Maranhão e Piauí para o corte de cana em São Paulo: será esse um fenômeno casual ou recorrente da estratégia empresarial do Complexo Agroindustrial Canavieiro? In: NOVAES, Roberto e ALVES, Francisco (Org's). Migrantes: trabalho e trabalhadores no Complexo Agroindustrial Canavieiro (Os heróis do Agronegócio Brasileiro). São Paulo: Ed. UFSCar, 2007. 
. Por que morrem os cortadores de cana? In: Saúde e Sociedade v. 15, n. 3, set-dez 2006, p. 90-98.

BAENINGER, Rosane, et.al. Regiões Canavieiras. Campinas/SP: NEPO/Unicamp, 2013.

BONFIM, Danilo. Cortadores de cana em Paraguaçu Paulista mantém paralisação. Disponível em:http://www6. rel-uita.org/sindicatos/cortadores_cana_paraguacu.htm. Acesso em: 13 Ago. 2013.

CARVALHO, Marisa. Greve de cortadores de cana chega a São Paulo. Disponível em:http://www.pstu.org.br/ node/12604. Acesso em: 13 Ago. 2013.

COLETTI. Claudinei. A Estrutura sindical no campo. Campinas: Ed. UNICAMP, 1998.

COSTA, Daniel; ARAÚJO, Fernando. Cofercatu dispensa cortadores em greve. Disponível em http:// www.gazetadopovo.com.br/economia/conteudo. phtml?id=974809. Acesso em: 13 Ago. 2013.

COVER, Maciel. O "Tranco da Roça" e a "Vida no Barraco": um estudo sobre trabalhadores migrantes no setor do agronegócio canavieiro. João Pessoa: Editora Universitária UFPB, 2011, $186 \mathrm{p}$.

FERRANTE, V. B Os herdeiros da modernização: grilhões e lutas dos "boias-frias". São Paulo em Perspectiva 8 (3), 1994.

Repensando um ciclo de greves. ln: ENCONTRO $\overline{D O P I P S A}, 12$ Campinas, 1987, Anais Botucatu, UEP, 1988, v.1, p. $1459-1522$.

Caminhos e descompassos do sindicalismo rural paulista. Perspectivas, São Paulo, 12/13: 73-102, 1989/90.

FOLHA DE SÃO PAULO. Termina a greve de cortadores de cana. Folha de São Paulo, quinta-feira, 28 ago. 2008.

FOLHA DE SÃO PAULO. Trabalhadores rurais entram em greve hoje em Sertãozinho. Disponível em http:// www.canaldoprodutor.com.br/comunicacao/noticias/ trabalhadores-rurais-entram-em-greve-hoje-emsertaozinho. Acesso em: 13 ago. 2013.

FREITAS, Geovani Jacó de. Ecos da violência: narrativas e relações de poder no Nordeste canavieiro. Rio de Janeiro: Relume Dará, 2003.

GUANAIS, Juliana B. No eito da cana, a quadra é fechada: estratégias de dominação e resistência entre patrões e cortadores de cana em Cosmópolis/SP. 2010. Dissertação

- (Mestrado em Ciências Sociais) - Programa de Pós-

굴 graduação em Ciências Sociais da Universidade Estadual ㄱ. de Campinas.

䢓

HERNANDES, Daniele. Cortadores de cana entram em greve em General Salgado Disponível em: http:// ฮี tn.temmais.com/noticia/9/52799/cortadores_de_cana o entram_em_greve_em_general_salgado.htm. Acesso em: ¥ 13 Ago. 2013

๓ొ MENEZES, M. O cotidiano camponês e a sua importância $\checkmark$ enquanto resistência à dominação: a contribuição de 2 James Scott. In Raízes v. 21 (01), 2002, p. 32-44.

$\stackrel{0}{1}$

. Redes e enredos nas trilhas dos migrantes. Um estudo de famílias de camponeses -migrantes. Rio de ô Janeiro: Relume Dumará/JP/UFPB, 2002.

$>$ MENEZES, M. SILVA, M.; COVER, M. Migrant Workers if in Sugarcane Mills: A Study of Social Networks and Recruitment Intermediaries in Brazil. In. Agrarian South: Journal of Political Economy, v. 1, p. 161-180, 2012.

( MONSMA, K. James C. Scott e a resistência cotidiana no campo: uma avaliação crítica. In: $B I B, R J$, n. $49,1^{\circ}$ semestre 눤 de 2000, p. 95-121.

NOVAES, J. R. O Conflito. Disponível em: http://advivo. com.br/blog/luisnassif/o-documentario-conflito-sobre-ostrabalhadores-da-cana. Acesso em: 09 Ago. 2013.
NOVAES, Roberto e ALVES, Francisco (Orgs). Migrantes: trabalho e trabalhadores no Complexo Agroindustrial Canavieiro (Os heróis do Agronegócio Brasileiro). São Paulo: Ed. UFSCar, 2007.

O DIARIO. Usina demite 205 cortadores de cana grevistas em SP. Disponível em: http://www.odiario.com/economia/ noticia/194028/usina-demite-205-cortadores-de-canagrevistas-em-sp/. Acesso em: 13 Ago. 2013.

O ESTADO DE SÃO PAULO. Cortadores de cana entram em greve. Disponível em: http://www.ihu.unisinos.br/ noticias/noticias-anteriores/11079-cortadores-de-canaentram-em-greve-companhia-e-acusada-de-maltratartrabalhadores. Acesso em: 13 Ago. 2013.

PORTAL CTB. Continua greve dos cortadores de cana na Usina Tamoio. Disponível em http://www.portalctb.org.br/ site/brasil/7456-continua-greve-dos-cortadores-de-canana-usina-tamoio. Acesso em: 13 Ago. 2013

PORTAL INDEPENDENTE. Sindicato afirma que 700 trabalhadores aderiram à paralisação; usina diz que são 400. Disponível em http://www.portalindependente. com.br/noticia/conteudo/2635/noticia.htm\#sthash. SCumdTlU.dpuf. Acesso em: 13 Ago. 2013

PORTAL MÍDIA INDEPENDENTE. Cortadores de cana em greve na Usina Decasa. Disponível em http://www. midiaindependente.org/pt/red/2008/11/432945.shtml. Acesso em: 13.08.2013

PORTAL PRUDENTINO. Sindicato diz que greve de trabalhadores da Decasa "é iminente" Disponível em http://www.portalprudentino.com.br/noticia/noticias. php?id=31230. Acesso em: 13 Ago. 2013

PORTAL VERMELHO. Em SP, PM confronta cortadores de cana; seis são feridos. (2008). Disponível http://www. sinprocampinas.org.br/?q=node/2118. Acesso em: 13 Ago. 2013

SADER, E. \& PAOLI, M.C. Sobre "classes populares" no pensamento sociológico brasileiro. In CARDOSO, R. (Org.) A aventura antropológica: teoria e pesquisa. Rio de Janeiro: Paz e Terra, 1986.

SAKAMOTO, Leonardo. Demissão de grevistas azedou lavouras de cana-de-açúcar. Disponível em: http:// blogdosakamoto.blogosfera.uol.com.br/2009/01/20/ demissao-de-grevistas-azedou-lavouras-de-cana-deacucar/. Acesso em: 07 Ago. 2013.

SCOPINHO, Rosemeire A. Qualidade total, saúde e trabalho: uma análise em empresas sucroalcooleiras. Revista de Administração Contemporânea, v. 4, n. 1, p. 93112, jan./abr., 2000.

SCOTT, J.C. The moral economy of the peasant. Rebellion and subsistence in southeast Asia. New Haven. Yale University, 1976

Formas cotidianas da resistência camponesa. In:

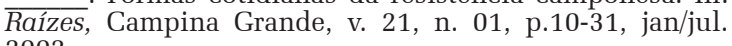
2002.

. Los dominados y el arte de la resistência. México: Ediciones Era, 1990.

Weapons of the weak: the everyday pratices of resistance. Yale University, 1985.

SILVA, Marcelo S. \& MENEZES, Marilda A. Entre o trabalhar e "dar trabalho": as formas de resistência dos migrantes paraibanos nos canaviais do estado de São Paulo. $3^{\circ}$ Encontro da Rede de Estudos Rurais. Campina Grande: 2008.

SILVA, Marcelo Saturnino. Entre o bagaço da cana e a doçura do mel: migrações e identidades da juventude rural. 2006. Dissertação (Mestrado em Ciências Sociais) - Programa de Pós-graduação em Ciências Sociais da Universidade Federal de Campina Grande. 
Trabalhadores-migrantes nos canaviais paulistas: sociabilidade, trabalho e formas de resistência. 2011. Tese (Doutorado em Ciências Sociais) - Programa de Pósgraduação em Ciências Sociais da Universidade Federal de Campina Grande.

SILVA, Marcelo Saturnino; NUNES, D. M. P.; COSTA, Polyana Felipe Ferreira. Trabalho e adoecimento no agronegócio canavieiro: um estudo das narrativas dos trabalhadores-migrantes nordestinos. In: VI Congresso Brasileiro de Ciềncias Sociais e Humanas em Saúde: circulação e diálogos entre saberes e práticas no campo da saúde coletiva - ANAIS. Rio de Janeiro: ABRASCO, 2013. p. 111.

SILVA, Maria Aparecida de Moraes. Errantes do Fim do Século. São Paulo. Editora da UNESP, 1999.

. Cortadores de cana e os (não) direitos. In: Travessia. São Paulo, CEM Maio-Agosto 2008 p. 26-36.

Trabalho e trabalhadores na Região do "Mar de $\overline{\text { cana e }}$ do rio de álcool". In: NOVAES, Roberto; ALVES, Francisco (Orgs). Migrantes: trabalho e trabalhadores no Complexo Agroindustrial Canavieiro (Os heróis do Agronegócio Brasileiro). São Paulo: Ed. UFSCar, 2007.
. A morte ronda os canaviais paulistas. Revista da Associação Brasileira de Reforma Agrária, v. 33, n. 2, Agosto/Dezembro 2006, p. 111-114.

SILVA, M. A. M.; BUENO, J. D.; MELO, B. M. Quando a máquina desfila, os corpos silenciam: tecnologia e degradação do trabalho nos canaviais paulistas. Contemporânea - Revista de Sociologia da UFSCar, v. 4, 2014, p. 85-116.

SILVA, Paulo Candido. Paradeiros e revoltas dos canavieiros alagoanos entre 2007/2009. 2011. Tese (Doutorado em Ciências Sociais) - Programa de Pós-graduação em Ciências Sociais da Universidade Federal de Campina Grande.

UNICA. UNICA considera irresponsável reportagem da BLOOMBERG TV. Disponível em: http://www.unica.com. $\mathrm{br} /$ noticia/33980888920331483908/unica-considerairresponsavel-reportagem-da-bloomberg-tv/. Acesso em: 25 Jun. 2014.

UITA. Rurais da região de Ribeirão Preto iniciam greve em três usinas de acúcar e álcool. (2008). Disponível em: http://www6.rel-uita.org/sindicatos/rurais_riberao_preto htm. Acesso em: 25 Jun. 2014. 


\section{“SPONTANEOUS” MOVEMENTS: resistance of immigrant workers in cane fields}

\author{
Marilda Aparecida Menezes \\ Maciel Cover
}

In this article we analyzed some forms of resistance of immigrant workers from rural areas of the Northeast region who work harvesting sugar cane for sugar-alcohol works in the state of São Paulo. More attention was given to the analysis of some "spontaneous" movements played by sugar cane harvesters - called "stopper" or "strike" that occurred from 2007 to 2012. Our goal is to understand these movements, how the action begins, are there leaders, what are the strategies used for mobilizing the workers, what other social actors are involved: unions, work attorneys and church groups. The article is based on field diaries, semi-structured interviews with workers and union members, newspaper articles and audiovisual documents. These resistance actions happen during a period of change in work relationships, influenced by the growing mechanization in sugar cane harvesting and a more strict control of work conditions promoted by the Department of Employment and Work and the Public Department of Work.

KEYwORDS: Immigrant workers. Public resistance. Strikes. Agribusiness.
MOUVEMENTS “SPONTANÉS”: la résistance des travailleurs migrants dans les champs de canne à sucre

\author{
Marilda Aparecida Menezes \\ Maciel Cover
}

Cet article présente l'analyse de la résistance des travailleurs migrants des zones rurales de la région nord-est qui font la récolte de la canne à sucre pour les usines productrices de sucre et d'alcool de l'État de Sao Paulo. Nous avons privilégié l'analyse de quelques mouvements "spontanés" organisés par les coupeurs de canne à sucre, désignés comme "arrêts" ou "grèves", qui ont eu lieu de 2007 à 2012. Notre propos est de comprendre ces mouvements, à savoir, comment ils commencent, s'il existe des leaders, quelles sont les stratégies utilisées pour mobiliser les travailleurs, quels sont les autres acteurs sociaux qui y participent: les syndicats, ceux qui vont à la recherche de ces travailleurs pour l'embauche, la pastorale des migrants. L'article se base sur les cahiers des charges, sur les interviews semi-structurées faites avec les travailleurs et les syndicalistes, des articles de journaux et des documents audiovisuels. Ces actions de résistance ont eu lieu au cours d'une période de transformations des rapports de travail marqués par un contexte de constante mécanisation de la coupe de la canne à sucre et par un contrôle des conditions de travail plus accru promu par le Ministère du Travail et de l'Emploi ainsi que par les Prud'hommes.

MотS-CLÉs: Travailleurs migrants. Résistance publique. Grèves. Agribusiness.

Marilda Aparecida Menezes - Doutora em Sociologia. Professora Visitante da Universidade Federal do ABC (PCHS) e do PPGCS/UFCG. Professora da Universidade Federal de Campina Grande. Pesquisadora do CNPq. Publicações recentes: Mobilidades, redes sociais e trabalho. 1a. ed. São Paulo: Annablume, 2011. 244p; Redes e enredos nas trilhas dos migrantes: um estudo de famílias de camponeses - migrantes. 1a. ed. Rio de Janeiro e João Pessoa: Relume Dumará e Ed. UFPB, 2002. 240p; Da usina ao assentamento: os dilemas da reconversão produtiva no Brejo Paraibano. Estudos Sociedade e Agricultura (UFRRJ), v. 21, p. 332-358, 2013; Família, juventude e migrações. Revista Anthropológicas, v. 23, n. 1, p. 119-143, 2012. Maciel Cover - Doutor em Ciências Sociais. Professor da Universidade Federal do Tocantins. Publicações recentes: Alojamentos de trabalhadores migrantes em usinas de cana de açúcar: espaço social de dominação e resistência. Iluminuras (UFRGS), v. 13, p. 85-103, 2012; Migrant workers in sugarcane mills: a study of social networks and recruitment intermediaries in Brazil. Agrarian South: Journal of Political Economy, v. 1, p. 161-180, 2012; O tranco da roça e a vida no barraco: um estudo sobre os trabalhadores migrantes no setor do agronegócio canavieiro. João Pessoa: Editora Universitária UFPB, 2011 